\title{
RECENT ADVANCES IN MENIERE'S DISEASE RESEARCH IN THE UNITED STATES
}

\author{
John J. Shea, M. D., T. J. Yoo, M. D., Ph. D. \\ Alec F. O'Connor, M. D., Koichi Tomoda, M. D.
}

Daniel J. Orchik, Ph. D.

The dominant fact of the inner ear is the very small volume of endolymph, 2.76 microliters in the normal human cochlear duct ${ }^{1}$ and approximately 20 microliters in the rest of the normal membranous labyrinth and endolymphatic sac. This is just a little more than $1 / 50$ th of one cubic centimeter. Awareness of this small volume puts everything else said about the inner ear and Meniere's disease into perspective.

Several recent examinations of collections of temporal bones in the United States have demonstrated that endolymphatic hydrops is more often found at autopsy than the diagnosis of Meniere's disease is made in life. ${ }^{2}$ (Figure 1) Part of this is due to the lack of suspicion of the disease by the clinician in the absence of the complete clinical picture of Meniere's disease. The rest is due to the lack of clearly defined criteria by which Meniere's disease can be diagnosed objectively by audiologic, radiologic, and other tests.

In an attempt to define the criteria by which Meniere's disease can be diagnosed we have created a worksheet upon which the historical and test information can be assembled, before and after treatment, so that minimal criteria can be established to make the diagnosis and evaluate the results of treatment.

(Figure 2)

\section{Audiologic History}

Information about hearing loss is recorded and hearing tests performed so as to be able to classify the patient according to the American Academy of Otolaryngology classification system.

\section{Audiologic Tests}

The slope of the audiogram is an important consideration when making the diagnosis and planning treatment since those with ascending slope have hydrops confined to the apex, flat have more extensive hydrops, and those with descending slope have widespread hydrops throughout the cochlea. (Figures 3 , $4,5,2)$ Since the membranous labyrinth has only a limited ability to recover after being expanded, it is logical that when hydrops is confined to the apex, and of recent origin, it would be more likely to disappear after surgical drainage of the membranous labyrinth than when it is widespread throughout the cochlea and of long duration.

The ipsilateral stapedial reflex occurs at 70 to 100 $\mathrm{dB}$ above air conduction threshold in normal, and in some other forms of sensorineural hearing loss, but in ears with Meniere's disease, in which recruit. ment is present, the stapedial reflex will appear at 40 to $55 \mathrm{~dB}$ above the threshold for air conduction, at approximately the same intensity it would appear if there were no hearing loss. ${ }^{3}$ (Figure 6)

We use the transcanal measurement of electrocochleography, after anesthesia of the ear canal and drum with iontophoresis with lidocaine. Coats et al found this to give good tracings if properly performed. ${ }^{4}$ This allo ws us to measure the cochlear microphonic, which shoud be present and no less than one microvolt, and the AP/SP complex. The negative summating potential is elevated in about $80 \%$ ears with endolymphatic hydrops of Meniere's disease and is the most important test to distinguish between Meniere's disease and other forms of sensorineural 
PATHOLOGY OF ENDOLYMPHATIC HYDROPS

SEVERITY AND DISTRIBUTION OF HYDROPS IN DIFFERENT OTOLOGICAL DISORDERS

\begin{tabular}{|c|c|c|c|c|}
\hline \multirow[t]{2}{*}{ Diagnosis } & \multirow[t]{2}{*}{ No. of persons } & \multirow[t]{2}{*}{ No. of bones } & \multicolumn{2}{|c|}{$\begin{array}{c}\text { Severity of endolymphatic } \\
\text { hydrops }\end{array}$} \\
\hline & & & Cochlear duct & Saccule \\
\hline Otosclerosis, post-operative & 14 & 15 & $\begin{array}{l}5 \text { severe } \\
2 \text { moderate } \\
8 \text { mild }\end{array}$ & $\begin{array}{l}3 \text { moderate } \\
4 \text { mild } \\
3 \text { fibrosis } \\
4 \text { normal }\end{array}$ \\
\hline Chronic otitis media & 2 & 3 & 3 moderate & $\begin{array}{l}1 \text { moderate } \\
2 \text { normal }\end{array}$ \\
\hline Congenital syphilis & 2 & 4 & $\begin{array}{l}2 \text { severe } \\
2 \text { moderate }\end{array}$ & $\begin{array}{l}2 \text { severe } \\
2 \text { moderate }\end{array}$ \\
\hline Presbycusis & 3 & 4 & $\begin{array}{l}2 \text { severe } \\
1 \text { moderate } \\
1 \text { mild }\end{array}$ & $\begin{array}{l}1 \text { mild } \\
3 \text { normal }\end{array}$ \\
\hline $\begin{array}{l}\text { Hereditary sensorineural } \\
\text { hearing loss }\end{array}$ & 2 & 3 & $\begin{array}{l}2 \text { severe } \\
1 \text { moderate }\end{array}$ & $\begin{array}{l}2 \text { severe } \\
1 \text { moderate }\end{array}$ \\
\hline $\begin{array}{l}\text { Acoustic neuroma } \\
\text { (post-operative) }\end{array}$ & 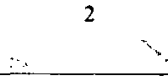 & 2 & $\begin{array}{l}1 \text { severe } \\
1 \text { mild }\end{array}$ & 1 mild \\
\hline Paget's disease & 1 & $\because:$ & 1 mild & 1 mild \\
\hline Normal & 2 & 2 & 2 mild & 2 mild \\
\hline $\begin{array}{c}\text { Menière's disease } ; \vdots ; \\
\ldots\end{array}$ & 9 & 11 & $\begin{array}{l}7 \text { moderate } \\
3 \text { moderate } \\
1 \text { mild }\end{array}$ & $\begin{array}{l}4 \text { severe } \\
2 \text { moderate } \\
2 \text { mild } \\
2 \text { fibrosis } \\
1 \text { collapse }\end{array}$ \\
\hline Others & 10 & 12 & $\begin{array}{l}6 \text { severe } \\
4 \text { moderate } \\
2 \text { mild }\end{array}$ & $\begin{array}{l}4 \text { severe } \\
2 \text { moderate } \\
3 \text { mild } \\
2 \text { artifact } \\
1 \text { normal }\end{array}$ \\
\hline TOTAL & 47 & 57 & $\begin{array}{l}25 \text { severe } \\
16 \text { moderate } \\
16 \text { mild }\end{array}$ & $\begin{array}{l}12 \text { severe } \\
11 \text { moderate } \\
15 \text { mild } \\
10 \text { normal } \\
3 \text { artifact } \\
5 \text { fibrosis }\end{array}$ \\
\hline
\end{tabular}

FIGURE 1 Pathology of Endolymphatic Hydrops 


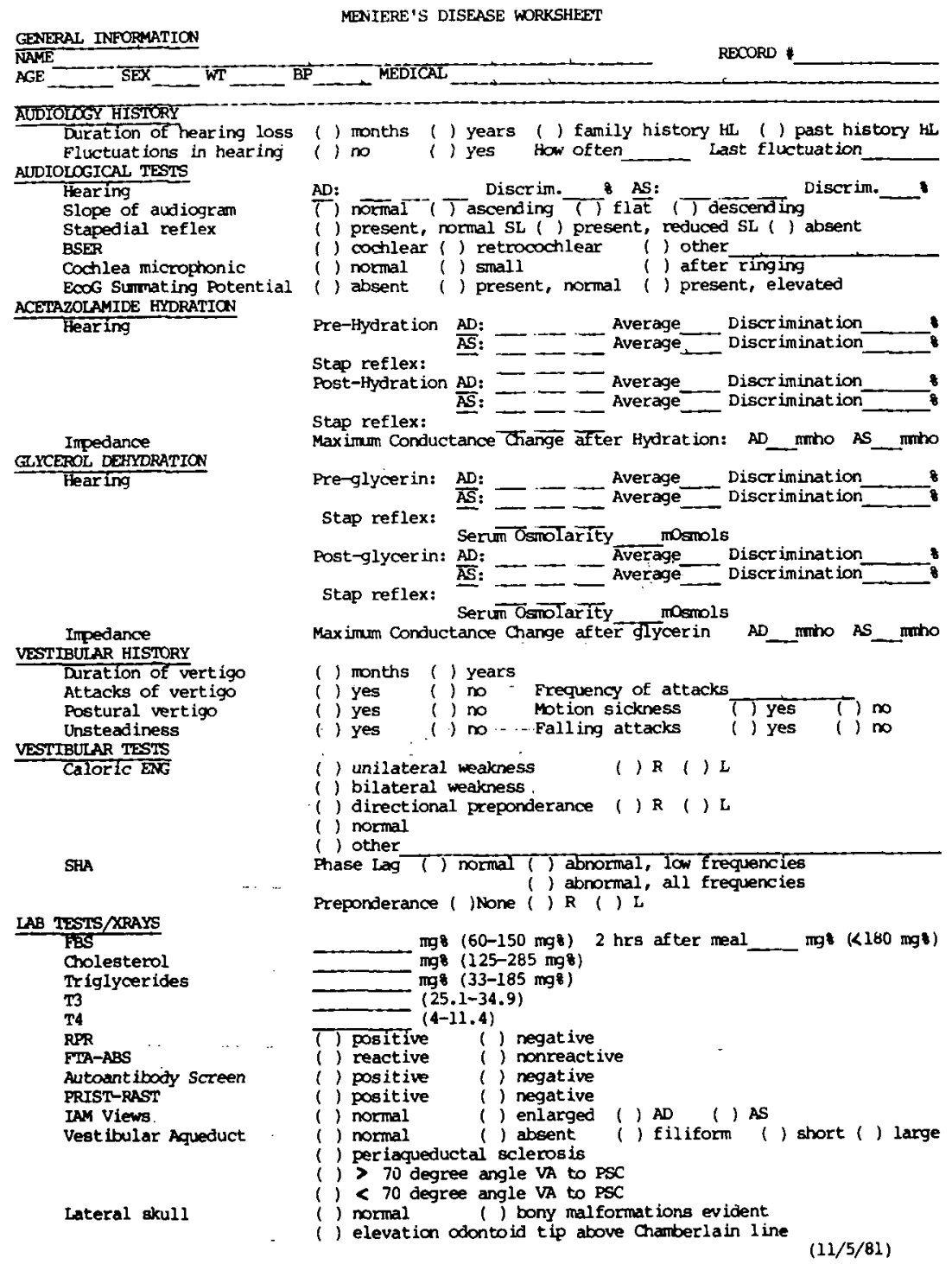

FIGURE 2 Meniere's Disease Worksheet 


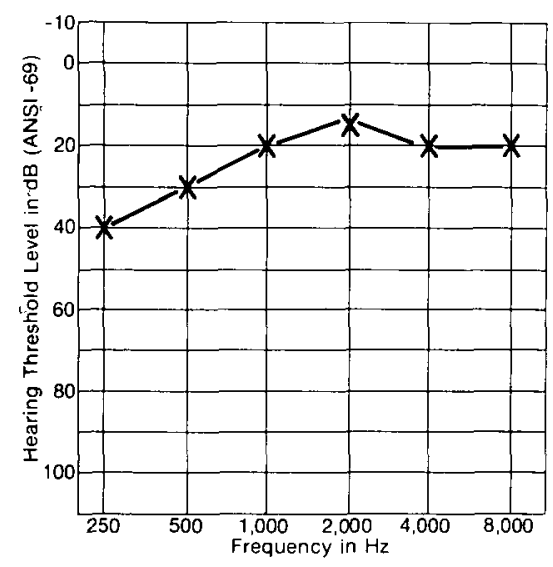

ASCENDING SLOPE

FIGURE 3 Audiogram showing ascending slope

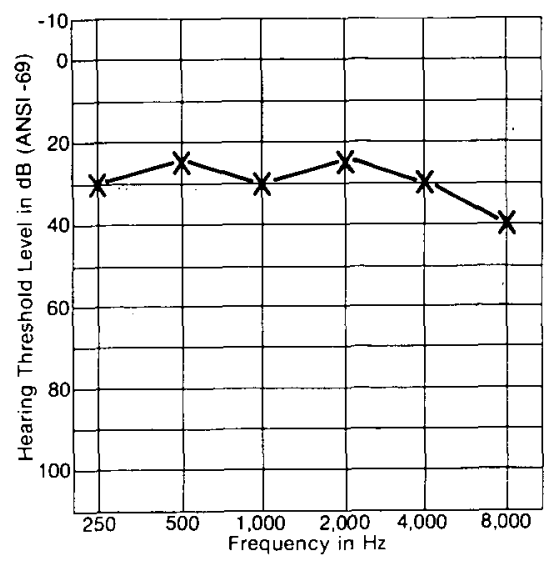

FLAT SLOPE

FIGURE 4 Audiogram showing flat slope

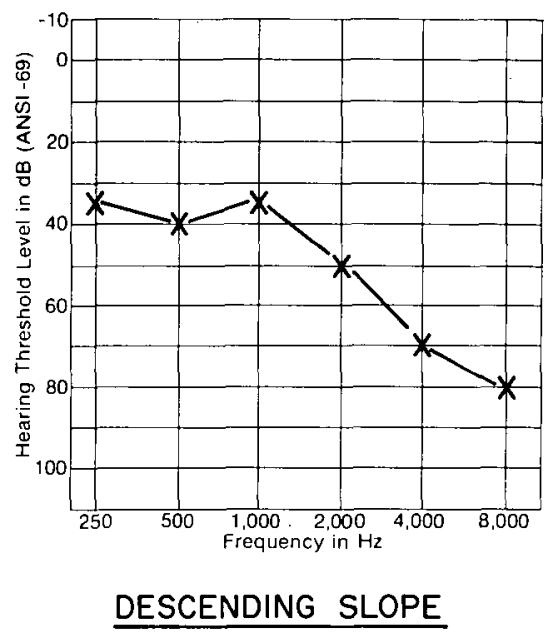

FIGURE 5 Audiogram showing descending slope 


\begin{tabular}{|c|c|c|}
\hline Ear & SRT & PB Max \\
\hline $\mathrm{A}$ & & \\
\hline $\mathrm{L}$ & & \\
\hline
\end{tabular}

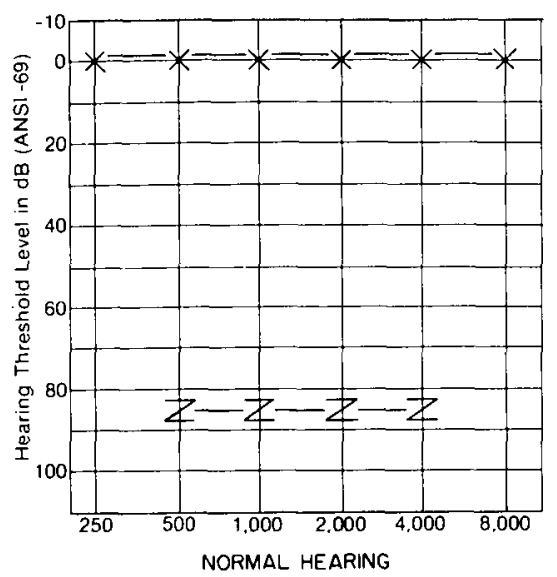

FIGURE 6 Stapedial reflex in Meniere's disease
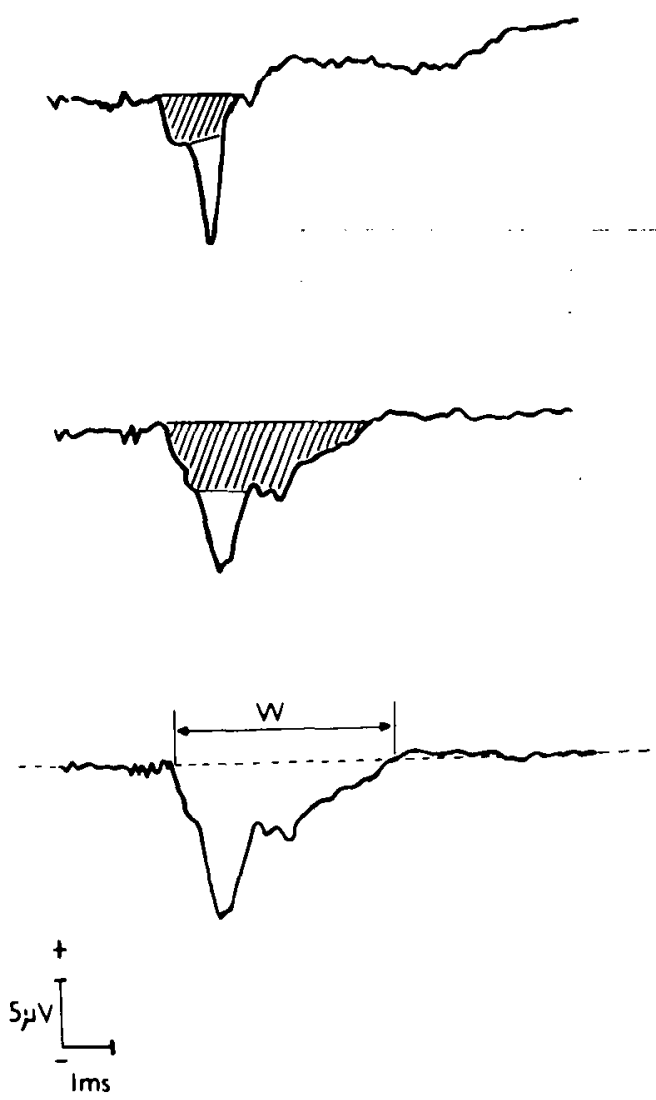

FIGURE 7 Summating potential in Meniere's disease 
ACETAZOLAMIDE HYDRATION TEST

500 mgm intravenous acetazolamide

Maximum results 15 to 30 minutes

Valid if $10 \mathrm{mill}$ iosmol decrease in osmolarity

Positive if:

Decrease in air conduction $10 \mathrm{~dB}$

Decrease in speech discrimination 108

Decrease in conductance 1 mmho

Increase in ipsilateral stapeciial reflex

FIGURE 8 Explanation of Acetazolamide $\mathrm{Hy}$ dration Test

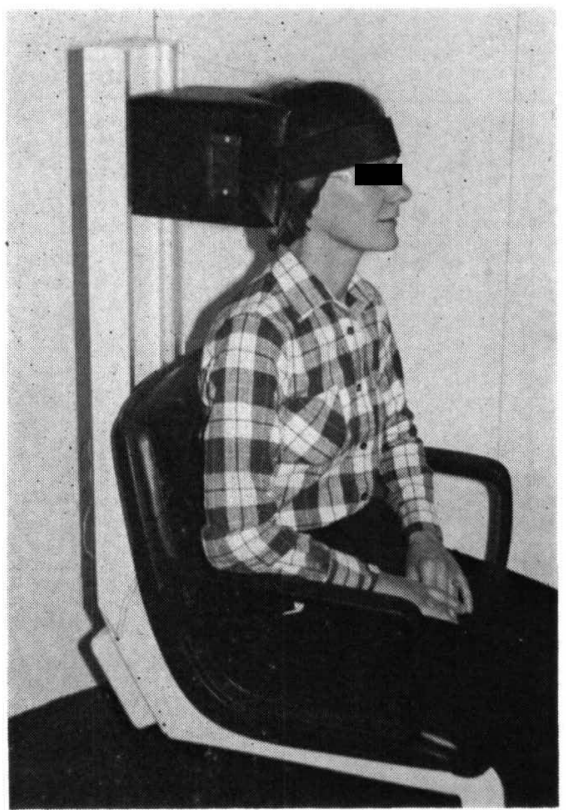

FIGURE 10 Slow Harmonic Acceleration Test Subject
GLYCEROL DEHYDRATION TEST

$11 / 2 \mathrm{cc} / \mathrm{kg}$ glycerol by mouth

Maximum results $11 / 2$ to 3 hours

Valid if $10 \mathrm{milliosmol}$ increase in osmolarity

Positive if:

Increase in air conduction $10 \mathrm{~dB}$

Increase in speech discrimination 108

Increase in conductance $1 \mathrm{mmho}$

Decrease in ipsilateral stapedial reflex

FIGURE 9 Explanation of Glycerol Dehydration Test

hearing loss, especially sudden hearing loss in which an elevated negative summating potential is never present.5) (Figure 7)

The brain stem evoked response is a measure of the electrical output of the ear from the eighth nerve to the inferior colliculus and is useful to distinguish between cochlear and retrocochlear patho$\log y$.

\section{Acetazolamide Hydration Test (Figure 8)}

In testing patients with Meniere's disease we have discovered that the intravenous acetazolamide (Diamox ${ }^{11)}$ ) hydration test, using changes in the ipsilateral stapedial reflexes, is easier to do and more objective than the glycerin dehydration test using changes in the pure tones and speech discrimination. ${ }^{2)}$ Maximum change in conductance in the middle and inner ear using a 660 cycle probe tone been demonstrated by O'Connor et al to be another objective measure of endolymphatic hydrops in making the diagnosis of Meniere's disease. In a positive test is a decrease in 
PATIENT: SHITH, MHEA CLINIC -- MEMPHIS EYE \& EAR HOSPITAL

PHASE LAG
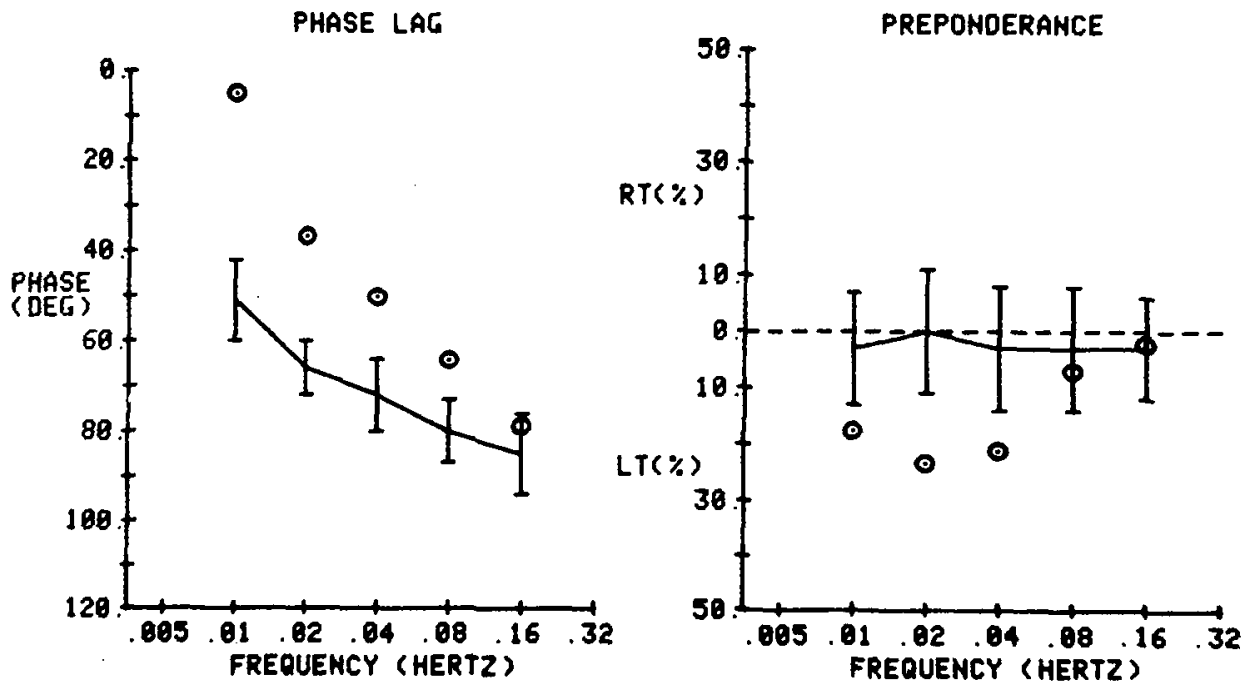

FIGURE 11 Slow Harmonic Acceleration Test Results

PATIENT: HELCH, LAEA CLINIC -- MEMPHIS EYE \& EAR HOSPITAL
DOCTOR: JJS TEST DATE: $10 / 29 / 8$
DISK FILE: LH2305.A2

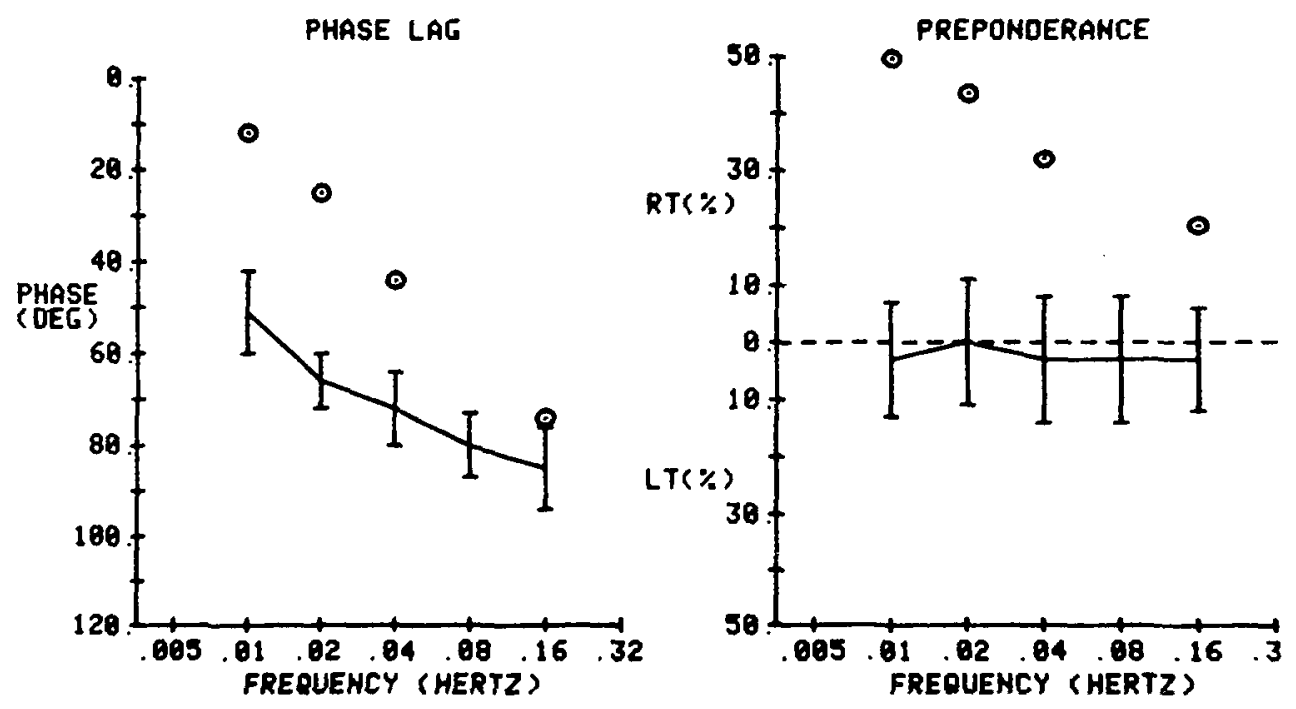

FIGURE 12 Slow Harmonic Acceleration Test Results 
maximum conductance of at least one mmho. ${ }^{6}$ )

A similar but opposite change takes place in the ear with Meniere's disease tested with glycerol.

\section{Glycerol Dehydration Test (Figure 9)}

Dehydration of the endolymph occurs when $11 / 2$ $\mathrm{cc} / \mathrm{Kg}$ of glycerol taken by mouth, the maximum effect being from one and one-half to three hours after ingestion. Tests of the serum must be made before ingestion and after one and one-half hours to verify that there was an increase of at least 10 milliosmols in the osmolarity of the serum to be sure the test was valid. A positive test occurs when there is an increase of at least $10 \mathrm{~dB}$ in pure tones or $10 \%$ in speech discrimination, or $10 \mathrm{~dB}$ in stapedial reflex thresholds, or an increase in maximum conductance of at least 1 milliohm.

\section{Vestibular History}

Information of duration and frequency of attacks of vertigo is recorded in such a way as to classify the patient according to the American Academy of Otolaryngology classification system.

\section{Vestibular Tests}

We now use the simultaneous bithermal binaural caloric electronystagmography by which we try to localize the side of the offending ear. Our results with this test are generally satisfactory, considering the time required and difficulty of the test. We hope to be able to determine the side of the offending ear, the presence of a hyperactive or hypoactive ear, or directional preponderance if it is present.

\section{Slow Harmonic Acceleration Test}

We are just beginning to assemble data on this test in which the subject is rotated back and forth in a harmonic motion at various speeds from 0.01 cycle per second to 0.16 cycles per second. The movement of the eyes in response to the motion is observed and the lag of the eyes relative to the motion of the head is recorded. While the side of the offending ear cannot be told by this test, one can distinguish between a central and a peripheral problem with great accuracy and the abnormal phase lag and preponderance characteristic of endoloymphatic hydrops of Meniere's return to normal after a successful shunt operation. (Figures 10, 11, 12)

\section{Lab Tests/Xrays (Figure 13)}

All necessary lab tests must be performed in patients suspected of Meniere's disease bacause the clinical picture of Meniere's disease can be caused by disorders of glucose, lipid, and thyroid metabolism. Proctor et al found abnormal glucose metabolism in 38 of 50 patients $(76 \%)$ with a diagnosis of Meniere's disease. ${ }^{7)}$

We measure RRR (reagin protein reactive) and ETA-ABS (fluorescent treponemal antibody absorp. tion test) on all patients suspected of Meniere's disease bacause syphilis, an autoimmune disease, can duplicate all signs and symptoms of Meniere's disease, but treatment is very different. Unless the patient

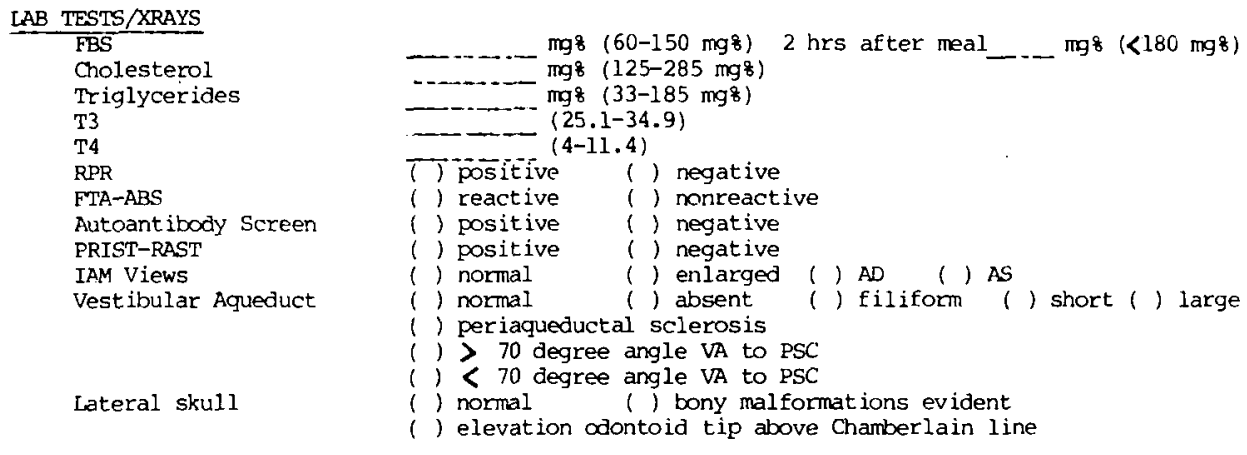

FIGURE 13 Lab Test/Xray Results, taken from Meniere's Disease Worksheet 


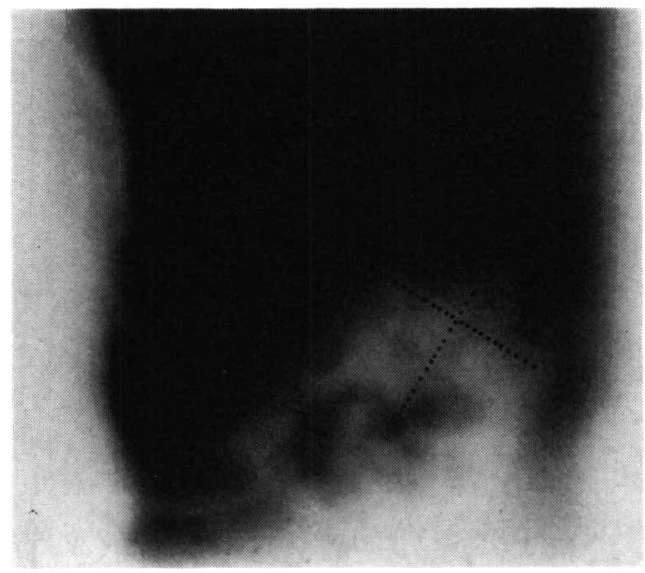

FIGURE 14 Angle between vestibular aqueduct and posterior canal: normal

with syphilis has never had adequate treatment with Penicillin there is no need to give it, since the hearing and balance are best treated with large doses of steroids only. ${ }^{\text {) }}$

Autoantibody screen, including lymphocyte migration inhibition test, is done in all patients suspected of autoimmune sensorineural hearing loss in addition to, or as a cause of, Meniere's disease.

PRIST-RAST test are done on patients suspected of classical allergy.

Petrous pyramid xrays to show the internal auditory canal must be made on all patients suspected of Meniere's disease to be sure there is there no acoustic neuroma, which can resemble Meniere's disease, or other pa thology.

Hypccycloidal polytomes of the vestibular aqueduct are necessary to learn if there is periaqueductal sclerosis and to observe the appearance and angle of the vestibular aqueduct with reference to the posterior semicircular canal. Wright et $a l^{8)}$ have observed that in patients with Meniere's disease this angle is usually less than 70 degrees, but in normals and other forms of hearing loss the angle is usually greater than 70 degrees. (Figures 14 and 15)

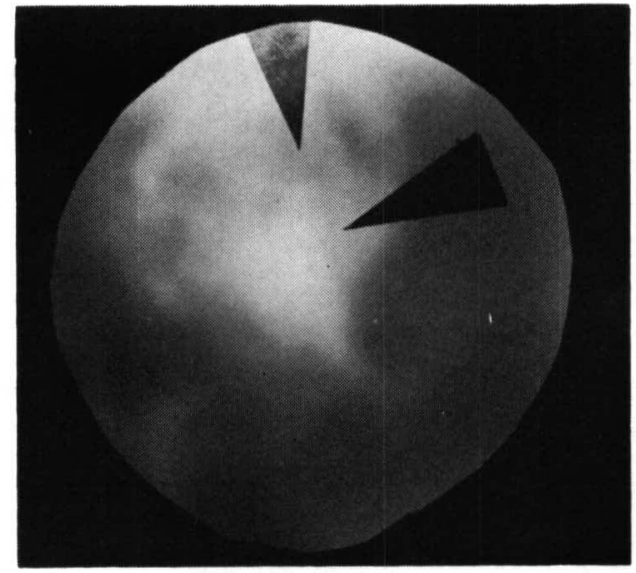

FIGURE 15 Angle between vestibular aqueduct and posterior canal : Meniere's Disease

We also look at a lateral xray of the skull to be sure there is no obvious bony malformation, and to observe whether the odontoid process rises above the Chamberlin's line, which Plester ${ }^{9)}$ found to be more frequent in patients with Meniere's disease.

(Figure 16)

\section{Early Subarachnoid Shunt}

Having performed the early subarachnoid shunt operation for many years it is obvious from this

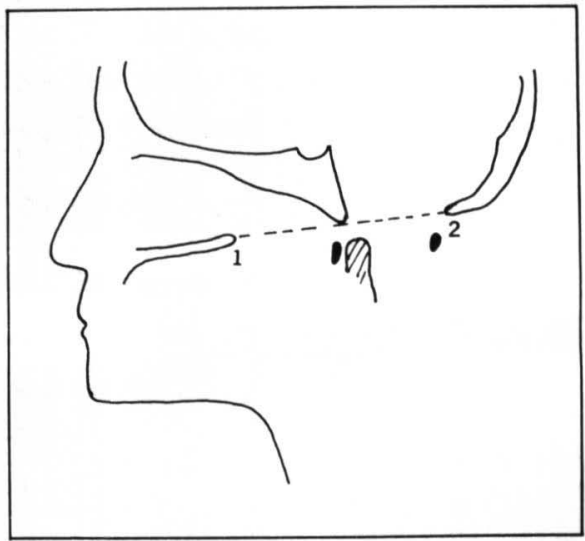

FIGURE 16a Chamberlain's line (from posterior edge of hard palate to posterior border of foramen magnum) 


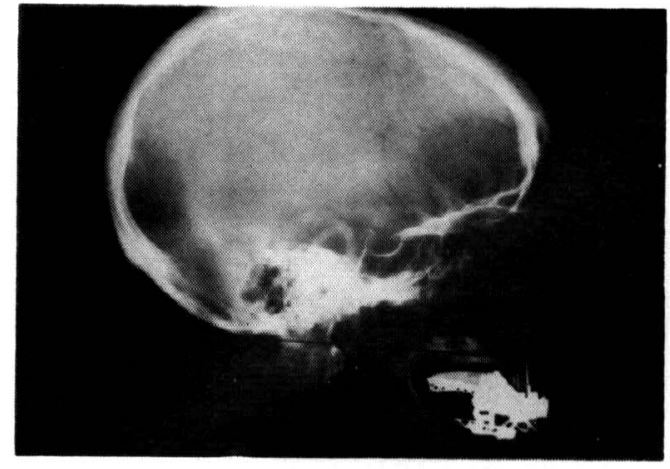

FIGURE 16b Normal Chamberlain's line

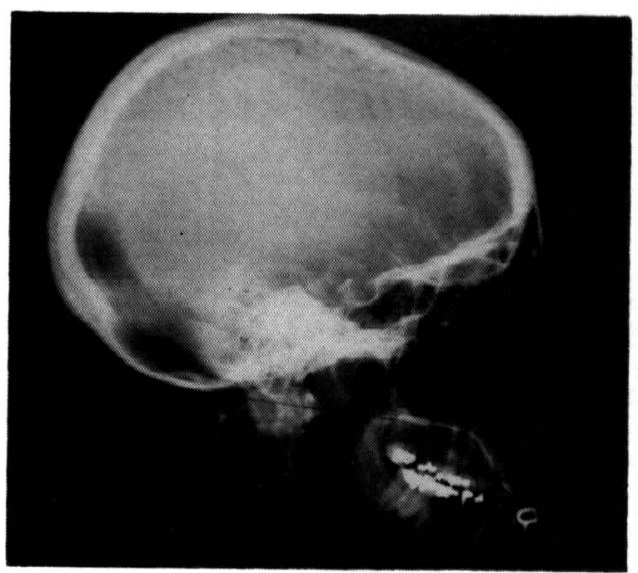

FIGURE 16c Abnormal Chamberlain's line

experience that if the hearing is to be preserved the diagnosis must be made early and the operation performed at once before irreversible hydrops takes place in the membranous labyrinth. For such patients I prefer the subarachnoid shunt, using a small silastic drain tube with an internal diameter of $0.8 \mathrm{~mm}$ in the sac near the duct as possible.

(Figure 17 and 18)

We have recently studied the results in a series of patients with early hydrops, defined as those with ascending slope, spontaneous fluctuations in learing, normal vestibular aqueducts, elevated negative summating potential, and positive glycerin test. It is not surprising that those with a large, normallooking sac in Type I, II, or III position according

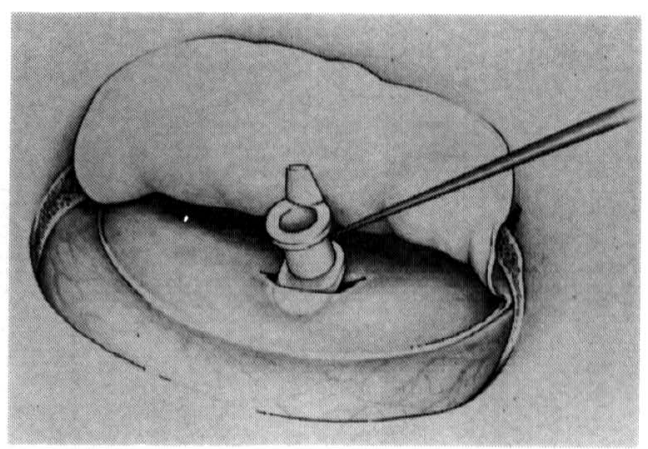

FIGURE 17 Small silastic shunt tube going into posterior wall of sac

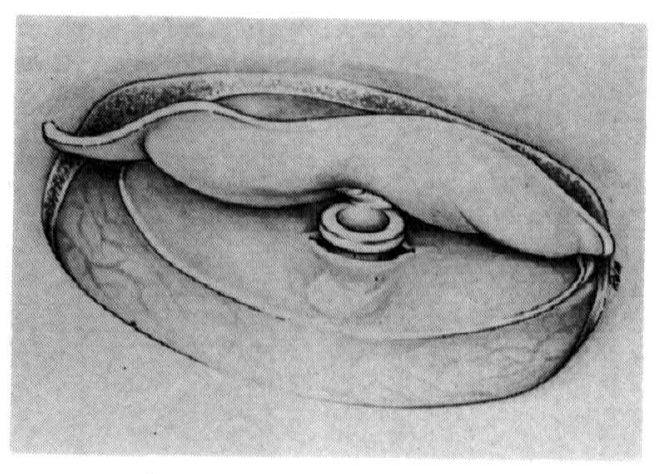

FIGURE 18 Lid of shunt tube covering opening to reduce chance of closure by ingrowth fibrous tissue

to be classification of Arenberg and Stahle ${ }^{10}$ did better than those in Type IV, and that those with normal vestibular aqueducts did better than those with filiform or nonvisualized vestibular aqueducts.

(Figure 19)

\section{Intracochlear Shunt}

For patients with more advanced hydrops I have developed an intracochlear shunt from the end of the cochlear duct into the scala tympani performed through the promontory. In these patients the vestibular aqueduct is either filiform or not visualized, the hearing loss 50 to $60 \mathrm{~dB}$ and non-fluctuating, with poor discrimination and repeated attacks of vertigo. Such a patient would be a candidate for vestibular neurectomy or labyrinthectomy. After opening the scala tympani the undersurface of the basilar mem- 
SUBARACHNOID SHUNT

$\mathbf{N}-30$

SLOPE OF AUDIOGRAM $\ldots \mathrm{N}-30$

$\begin{array}{lcrr} & \text { BETTER } & \text { SAME } & \text { WORSE } \\ \text { 1. ASCENDING } & 508 & 368 & 148 \\ \text { 2. COOD FIFT } & -- & 868 & 148 \\ \text { 3. FLAT } & - & 1008 & --\end{array}$

\begin{tabular}{lcccc} 
& \multicolumn{2}{c}{ GLYCERIN TEST } & N -23 \\
& & BETTER & SAME & WORSE \\
1. POSITIVE & 578 & 298 & 148 \\
2. NEGATIVE & 238 & $65 \%$ & 128
\end{tabular}

$\begin{array}{lcrr} & \text { SUMATING POTENIIAL } & \text { N-16 } \\ \text { 1. PRESENT, NORMAL } & \text { BEITER } & \text { SAME } & \text { WORSE } \\ \text { 2. ARSENT } & -1008 & - \\ \text { 3. PRESENT, ELEVATED } & 228 & 648 & 148\end{array}$

$\begin{array}{llccc} & \text { VESTIBULAR AQUEDUCT } & \mathrm{N}-28 & \\ & & \text { BETTER } & \text { SAME } & \text { WORSE } \\ \text { 1. NORMAL } & 338 & 56 \% & 118 \\ \text { 2. ABSENI } & 228 & 568 & 228 \\ \text { 3. FILIFORM } & 508 & 408 & 108\end{array}$

$\begin{array}{lrrrr} & \text { LOCATION OF SAC } & \mathrm{N}-30 \\ \text { 1. I } & & \text { BETIER } & \text { SAME } & \text { WOASE } \\ \text { 2. II } & \text { II } & 608 & - \\ \text { 3. III } & 298 & 428 & 298 \\ \text { 4. IV } & 418 & 478 & 128\end{array}$

FIGURE 19 Results of early subarachnoid shunt

brane is exposed, and found to be buldging down ward. A small puncture is made in the mambrane, endolymph is out and the basilar membrane returns to its normal position. The patient is much improved at once, free of attacks of vertigo, although unstead. iness remains for a while, much as it does after labyrinthectomy. The hearing decreases at once but returns slowly to the preoperative level as the punc. ture heals with a small filtering bleb that will, hopefully, continue to drain enough endolymph to pre-

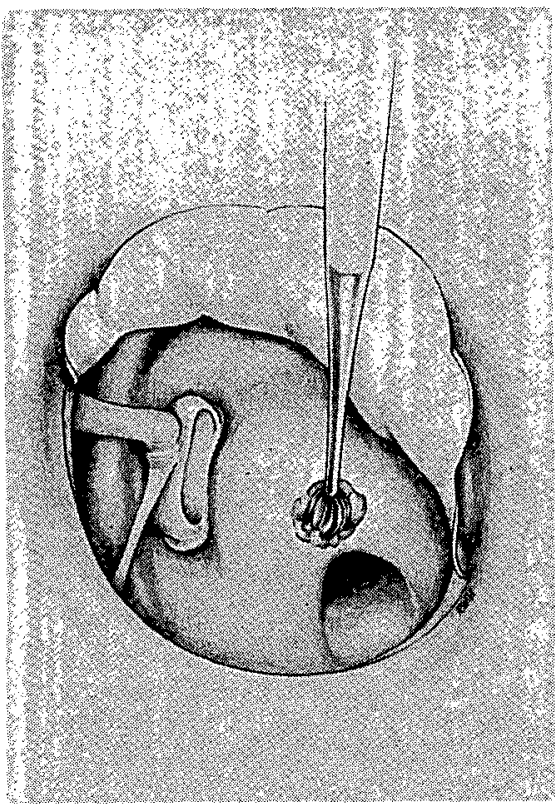

FIGURE 20 Creating opening in scala tympani between oval window and round win. dow

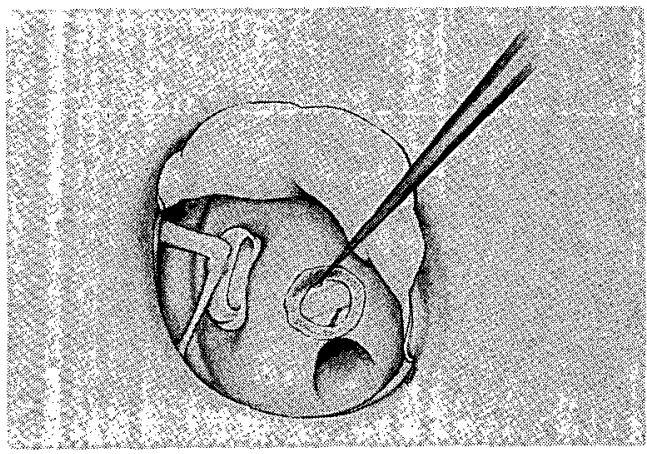

FIGURE 21 Creating shunt in undersurface of basilar membrane

vent further attacks of dizziness. (Figures 20, 21 \& 22)

\section{Autoimmune Sensorineural Hearing Loss}

Some patients thought to have classical Meniere's disease only have something like autoimmune sensorineural hearing loss also since they respond to large doses of steroids. One young man of 32 with extreme 
fluctuations in hearing in both ears, with labyrinthectomy in one and mastoid shunt in the other, responded dramatically to $4 \mathrm{mgm} \mathrm{DMZ}$ for three months. (Figures 23, 24\&25) The exact role of autoimmune sensorineural hearing loss in Meniere's disease remains to be seen but we are suspicious it plays a part, even a large part, in many patients with Meniere's disease. ${ }^{11}$ Lymphocyte migration inhibition tests using human membranous labyrinth as the antigen and immunoassay tests using purified collagen type II, like that present in the human otic capsule, were performed on a series of patients with a confirmed diagnosis of Meniere's disease. In 18 of 40 such patients, both tests were positive, leading us to believe an autoimmune response was at least partially responsible for the changes in the inner ear.

We are now expanding our autoimmune investigations of patients with confirmed and suspected Meniere's disease. We have, in addition, created an animal model of Meniere's disease in the rat, using purified collagen type II as the stimulant.

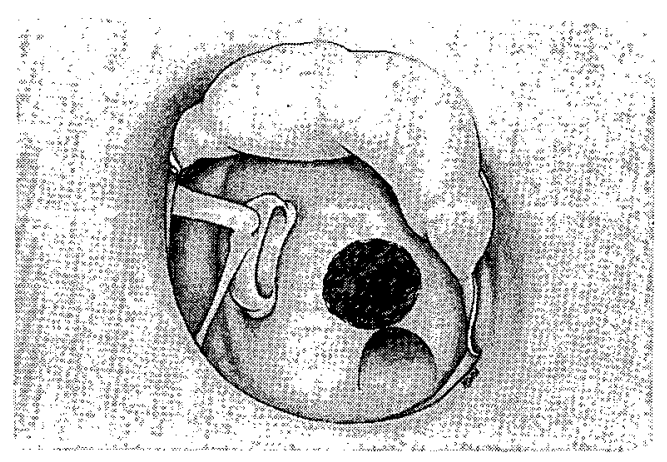

FIGURE 22 Closure of opening in scala vestibule with Proplast TM

At the present time, we are trying to create the perisaccular fibrosis of Meniere's disease in the guinea pig by autoimmune response. ${ }^{12}$ )

\section{SUMMARY AND CONCLUSIONS}

The recent advances in Meniere's disease research in the United States have been on all fronts, in

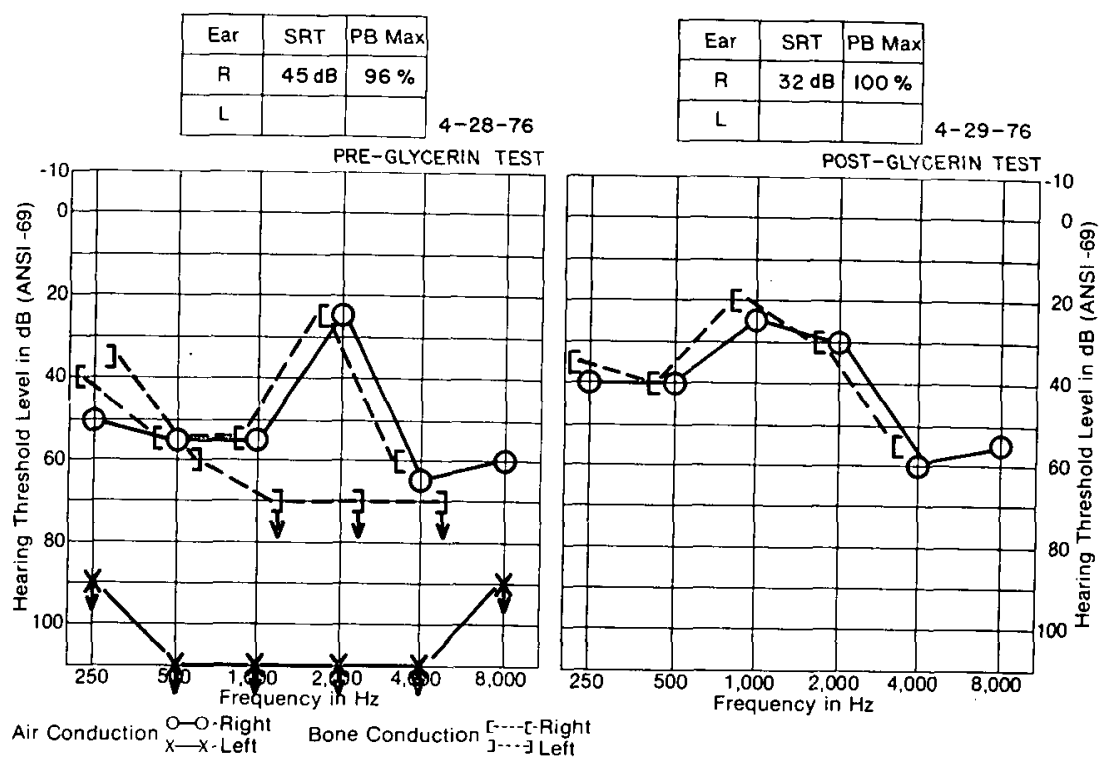

AUTOIMMUNE SNHL

58910 (FIRST CHART OF THREE) 9-8I

FIGURE 23 Autoimmune sensorineural hearing loss 


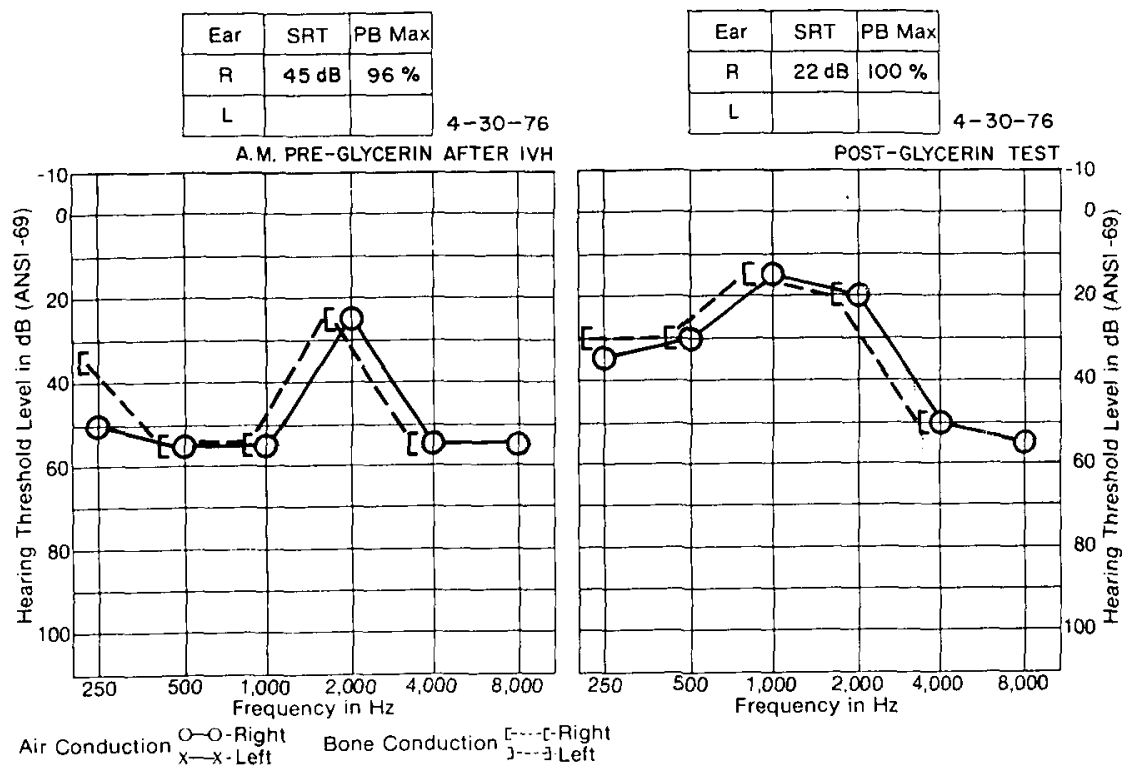

\section{AUTOIMMUNE SNHL}

58910 (SECOND CHART OF THREE) 9-3I

FIGURE 24 Autoimmune sensorineural hearing loss

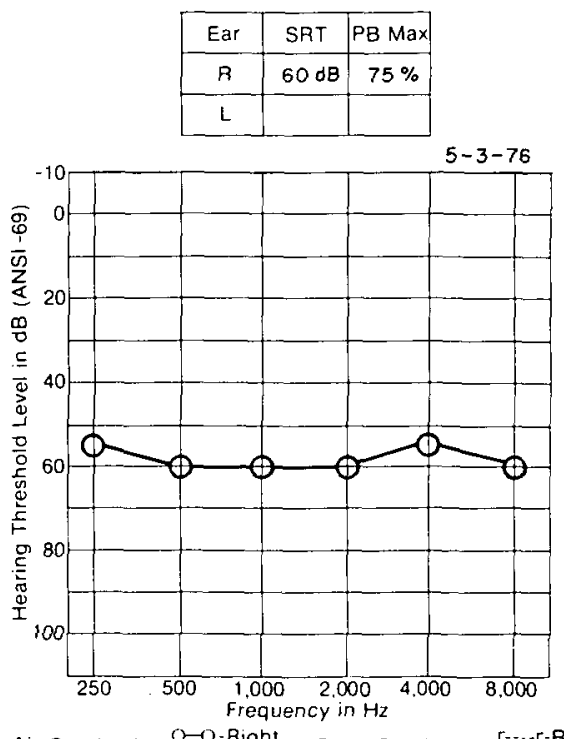

Air Conduction $\begin{aligned} & 0-O \text {-Right } \\ & x \rightarrow-\text {-Left }\end{aligned}$

\begin{tabular}{|c|c|c|}
\hline Ear & SRT & PB Max \\
\hline$R$ & $18 \mathrm{~dB}$ & $96 \%$ \\
\hline $\mathrm{L}$ & & \\
\hline
\end{tabular}

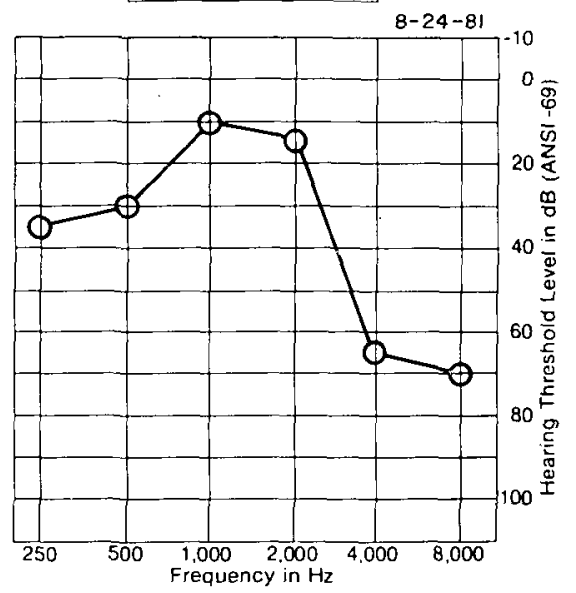

AFTER GLYCERIN TEST

AFTER $4 \mathrm{mgm}$ DEXAMETHASONE

FOR 3 MONTHS

$58910 \quad|1-8|$

FIGURE 25 Autoimmune sensorineural hearing loss 


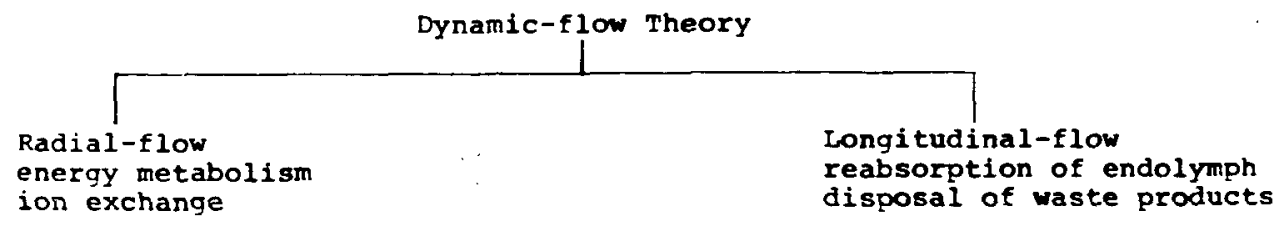

FIGURE 26 Dynamic Flow Theory Chart

understanding the pathology and pathologic physiology of Meniere's disease, the natural history of the disease, and in testing to verify the presence of endolymphatic hydrops, and in various forms of medical and surgical treatment.

The electrocochleography, using the acetazolamide hyaration and glycerol dehydration tests, has added greatly to our understanding of Meniere's disease.

The continued investigation of the vestibular aqueduct by hypocycloidal polytome and in the future with CAT scanning has increased our understanding of the cause of idiopathic endolymphatic hydrops and the likelihood of benefit from operations on the endolymphatic sac.

The observation that ears with Meniere's disease have an angle of less than 70 degrees between the vestibular aqueduct and the posterior semicircular canal as compared to normals in which the angle is always greater than 70 degrees will be, if true, very helpful in quantifying the diagnosis of Meniere's disease.

Continued interest in early operations on the endolymphatic sac should increase information about the value of this procedure. Clearly the treatment for Meniere's disease must recognize it for what it is, an insidious, usually progressive but extremily variable disorder of the inner ear. Without question the funda-mental cause is developmental, a small, misplaced Early in life the regulation of fluid balance in the sac. inner ear begins to be compromised but there is enough excess capacity in the system to compensate for the small inadequate sac. The Dynamic Flow Theory of Lundquist ${ }^{13}$ (Figure 26) best explains the probable sites of production and absorption of endo. lymph and the roles of the stria vascularis and the endolymphatic sac. At this point there may be an insult to the system, to the stria vascularis and/or the endolymphatic sac, to disturb this already compromised equilibrium. This insult may be chemical, as by overloading the body with sodium and hence we believe the real but as yet unproven value of salt restriction and potassium-sparing diuretics in the management, not cure, of Meniere's disease in the early, still fluctuating stage. This insult may be metabolic, from disorders of glucose and/or lipid metabo lism, hence the very real obvious value of correcting these disorders when present. This insult may be autoim mune, the exact trigger for which remains to be found, hence the large number of patients with Meniere's disease with positive tests of autoimmunity to purified collagen likely to be present in the inner ear and the remarkable response in some patients to large doses of steroids. The insult may be other as yet unproven wtimuli shich remain to be found.

Once this insult to the system takes place, the already compromised equilibrium is overwhelmed, the disease enters the uncompensated phase and hydrops of the cochlear and/or vestibular labyrinth occurs, and corresponding signs and symptoms appear. Most patients are first seen by the doctor after the system is compromised and treatment must be consistent with the situation which exists. That is why we have attempted to make the diagnosis early, before the system is compromised, and do the subarachnoid endolymphatic shunt early, which seems to us the most reasonable thing to be considering all the circumstances existent at that time.

After the system is compromised, the hearing is down, flat, or descending, non-fluctuating and attacks of vertigo are regular and frequent, the best opera- 
tion is something else. The observation by Kitahara et al that there is a value in the guinea pig which prevents reflux of liquid from the sac into the vesti. bule $^{14}$ and the probable existence of such a value in the human makes the operations on the sac by House $^{(5)}$, Arenberg ${ }^{(6)}$ and Kitahara ${ }^{14)}$ and others more reasonable, because by the time the sac is so compromised it is not functional, and to open it up into the rugose position at least drains the system once and perhaps affords some continued draining of endolymph. With a large plastic drain tube in the widcly opened sac, it will not function in the usual way any longer.

This theory also offers some support to those like Austin ${ }^{17)}$ and others who have found the subarachnoid shunt to be more effective in patients with a visible vestibular aqueduct than in those in which it is not.

The intracochlear shunt, if it proves to be as effective long-term as it is now, will be a great help in controlling vertigo in ears with a fliform or nonvisualized vestibular aqueduct and severe nonfluctuant hearing loss.

It may be that an autoimmune insult to the stria vascularis and/or the endolymphatic sac is what triggers the development of endolymphatic hydrops in the ear with a small, badly placed abnormal sac. Much needs to be done to clarify the role of autoimmunity in Meniere's disease. We have already located and successfully treated some patients thought to have Meniere's disease only with large doses of steroids.

\section{REFERENCES}

1) Maggio, E.: The humoral system of the labyrinth. Acta Otolaryngol, Suppl. 218, 1966.

2) Belal, A., Antunez, J.C. : Pathology of endolympha tic hydrops. J. Laryngol. Otol. 94: 1231-1240, 1980.

3) O'Connor, A.F, Shea, J.J., Orchik,D.J.: Stapedial reflex in Meniere's disease. In publication.
4) Coats, A.C. : Ear-canal-recorded summating potential and Meniere's disease. Unpublished proposal.

5) Morrison, A.W., Moffat, D.A., O'Connor, A.F.: Clinical usebulress of electrocochlegraphy in Meniere's disease : an analysis of dehydrating agents. Otolaryng. Clin. N. Am. 13 (4) : 763-721, 1980.

6) O'Connor, A.F., Morrison, A.W., Shea, J.J. : Glycerol induced changes of acoustic conductance in Meniere's disease. In publication.

7) Pillsbury, H.C., Shea, J.J.: Luetic hydropsdiagnosis and therapy. Laryngoscope 89: 11351144, 1979.

8) Wright, W.L. : Personal communication.

9) Plester, D., Elies, W.: Diagnosis and treatment of cranio-cervical dysplasia. Proceedings of the Sixth Shambaugh International Workshop on Otomicrosurgery and Third Shea Fluctuant Hearing Loss Symposium, Strode Publishers, Inc., Huntsville, Alabama, 1981.

10) Arenberg, I.K., Rask-Andersen, H., Willbrand, H., Stahle, J.: The surgical anatomy of the endolymphatic sac. Arch. Otolaryngol. 103: 1-11, 1977.

11) Yoo, I.J., Shea. J.J. : Autoimmune sensorineral hearing loss in Meniere's disease. In publication.

12) Tomoda, K., Shea, J.J.: Experiments in creation of perisaccular fibrosis. In publication.

13) Lundquist, P.G.: Aspects on endolymphatic sac morphology and function. Arch, Oto-RhinoLaryngol. 212: 231-240, 1976.

14) Kitahara, M., Takeda, T., Yazawa, Y., Matsu-

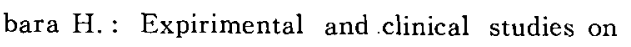
epidural drainage surgery. In publication.

15) House, W.F.: Subarachnoid shunt for drainage of endolymphatic hydrops. Laryngoscope $72: 713-$ $729,1962$.

16) Arenberg, I.K., Stahle, J., Wilbrand, H., Newkirk, J.B. : Unidirectional inner ear valve implant for endolymphatic sac surgery in Meniere's disease. Arch. Otolaryngol, 104: 694-704, 1978.

17) Austin DF : Use of polytomography in Meniere's disease. Arch. Otolaryngol, 106: 377-382, 1980. 